\title{
Methylated Septin9: biomarker for diagnosis of cervical cancer in cervical scrapings and for prediction of pelvic lymphatic metastasis in plasma
}

Qiaowen Bu ( $609360641 @ q q . c o m$ )

Guangdong Women and Children Hospital Heng-ying Wu

Guangdong Women and Children Hospital

\section{San-feng Wang}

Guangdong Women and Children Hospital Jian Ma

Guangdong Women and Children Hospital

\section{Wen Lei}

Guangdong Women and Children Hospital

\section{Yu-han Li}

Guangdong Women and Children Hospital

\section{Wei-ping Zhou}

Guangdong Women and Children Hospital

\section{Hai-ping Li}

Guangdong Women and Children Hospital

Hua Deng

Guangdong Women and Children Hospital

Jia-qi Luo

Guangdong Women and Children Hospital

Lu-lu He

Guangdong Women and Children Hospital

Liang Zhang

Guangdong Women and Children Hospital

Xi-ping Luo

Guangdong Women and Children Hospital

\section{Research}


Keywords: Septin9, DNA methylation, cervical cancer, pelvic nodal metastasis, circulating tumor DNA, cervical scrapings, quantitative methylation-specific PCR(qMS-PCR)

Posted Date: April 29th, 2020

DOI: https://doi.org/10.21203/rs.3.rs-22142/v1

License: (c) (1) This work is licensed under a Creative Commons Attribution 4.0 International License. Read Full License 


\section{Abstract}

\section{Background}

Aberrant Septin9 methylation in cervical cancer has been rarely studied. In this study we aimed to identify its diagnostic value of cervical cancer in cervical scrapings, and its predictive potential in plasma for pelvic nodal metastasis of cervical cancer.

\section{Methods}

The statuses of methylated Septin9 in fresh cervical lesions were first evaluated by using quantitative methylation-specific PCR(qMS-PCR). Subsequently 248 samples of cervical scrapings were collected to explore Septin9 methylation in different severities of cervical lesions; and the relationship between Septin9 methylation in plasma and pelvic nodal metastasis of cervical cancer was further evaluated.

Results

Methylated Septin9 was detected in all cancerous tissues, but not in cervicitis controls $(P<0.0001)$. The degrees of Septin9 methylation increased with growing severity of cervical lesions in cervical scrapings $(P<0.0001)$. Methylation analysis of Septin9 demonstrated a satisfactory specificity and area under the curve(AUC) in cervical cancer detection, at an equivalent sensitivity relative to any other test. And methylated Septin9 also yielded a high specificity and AUC in detecting high-grade squamous intraepithelial lesion or cervical cancer( $\geq$ HSIL). Plasma-based Septin9 methylation had a high discriminatory power in predicting pelvic nodal metastasis, with an optimal specificity of $81.48 \%$; additionally an increasing sensitivity from $50 \%$ to nearly $80 \%$ was found when combined with squamous cell carcinoma antigen(SCC-Ag).

\section{Conclusions}

In conclusion, we demonstrated methylated Septin9 to be an innovative diagnostic biomarker for cervical cancer in cervical scrapings and its non-invasive predictive potential in plasma for pelvic nodal metastasis of cervical cancer.

\section{Background}

Cervical cancer ranks as the fourth most common gynecologic malignancy and the fourth leading cause of cancer deaths among women worldwide, posing a serious threat to women's health[1]. Although cytologic and HPV-DNA tests have become available for cervical cancer screening, a substantial number of (pre)cancerous lesions have been missed for modest sensitivity of cytology; and result in unnecessary over-referral of colposcopy due to low specificity for CIN $\llbracket$ or cervical cancer ( $\geq \mathrm{CIN} \rrbracket)$ of HPV-DNA testing[2]. Therefore, it is of paramount importance to find specific biomarkers for the detection of cervical cancer that possess a comparable sensitivity but with increased specificity. Persistent high risk 
methylation are also the key triggers of the carcinogenic process. Many genes, including PAX1, SOX1, PCDHA, DCC, EPB41L3, and FAM19A4, have been confirmed to be hypermethylated in cervical scrapings

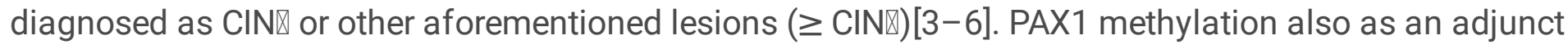
screening method for cervical cancer has been approved by Taiwan FDA[7], laying the foundation for the future application of more biomarkers to the diagnosis of carcinoma.

The status of pelvic nodal metastasis is associated with prognosis and determines the postoperative treatment of cervical cancer[8]. Therefore, pelvic lymphadenectomy is a standard procedure for radical hysterectomy in women with early-stage cervical cancer (Stages IA to IB1), but only $10 \%$ of patients with cervical cancer have metastatic disease after surgery[9]. Importantly, pelvic lymphadenectomy increases surgical complications and postoperative lymphedema[10]. Therefore, it is important to explore minimally invasive technologies that allow recognition of pelvic nodal metastasis. Recent studies have indicated that some methylated genes in plasma are closely associated with metastasis of cervical cancer[11]. Methylated Septin9 in circulating tumor DNA (ctDNA) has been widely utilized in colorectal cancer screening, diagnosis, and monitoring[12]. In addition, methylated Septin9 has proven to be a potential biomarker for several other tumors including gastroenteric cancer[13-14], breast cancer[15], lung cancer[16], liver cancer[17], head and neck squamous cell carcinoma[18], pancreatic cancer[19], as well as cervical cancer[20], indicating Septin9 methylation is not tissue specific. Therefore, whether ctDNAbased methylation analysis of Septin9 may provide a non-invasive approach to predicting pelvic nodal metastasis in cervical cancer?

We previously identified a significant growing FAM19A4 methylation in cervical scrapings from (pre)cancerous lesions compared with no-CIN lesions[21]. In this research, based on these results, we further investigated the diagnostic value of Septin9 methylation in cervical cancer scrapings and its predictive accuracy of pelvic lymphatic metastasis in plasma of cervical cancer.

\section{Methods}

\section{Study population}

\section{1. cervical fresh tissues and scrapings}

We initially included eight cervical cancer tissues confirmed by pathology from Guangdong Women and Children Hospital, and corresponding controls from nine cervicitis without HPV infection. These samples were preserved by RNAstore solution (CWBiotech company, Beijing, China) for subsequent methylation analysis.

We further recruited cervical scrapings on 1050 hrHPV-positive patients aged 20-65 years, who visited the study hospital between November 2016 and May 2018. All participants voluntarily accepted cervical HPV-DNA genotyping and cytologic tests. Samples of cervical scrapings were collected by experienced avnornlnaictc wcinn a norvinal nutnhruch $\triangle$ ftor coraoning the specimens, 248 patients histologically Loading [MathJax]/jax/output/CommonHTML/fonts/TeX/fontdata.js 
confirmed with cervical cancer, HSIL, LSIL, or no-CIN lesions were included in the study. (Flowchart in Fig. 1A)

\subsection{Peripheral Blood Of Cervical Cancer}

In addition, peripheral blood samples from 148 patients with cervical cancer (stages IA to IIB) were collected before surgery from August 2017 to August 2018. Eventually, only 113 samples met the selection criteria and were included in our final analysis (Flowchart in Fig. 1B). Whole blood was collected into a Cell-Free DNA Storage Tube (GenePhar Technologies Inc., Guangzhou, China) and stored for no more than 10 days at room temperature before centrifugation to isolate plasma.

We acquired the corresponding samples and complete clinical data of participants who contributed scrapings and plasma. Exclusion criteria included pregnancy, lactation, miscarriage in the past six months, chronic or acute systemic viral infections, skin or genital warts, a history of hysterectomy, a history of cervical neoplasia, and current or previous history of other cancers. Approval for this study was obtained from the Guangdong Women and Children Hospital Ethics Committee (reference number, 201901018). We obtained informed written consent prior to specimen collection, according to institutional guidelines.

\section{Cervical HPV-DNA genotyping, cytologic testing and colposcopic biopsy}

HPV-DNA genotyping tests were detected in the Department of Clinical Laboratory at our hospital by fluorescence quantification PCR in accordance with the manufacturer's instructions (Kaipu Company, China). This method could identify 14 hrHPV genotypes (HPV-16, 18, 31, 33, 35, 39, 45, 51, 52, 56, 58, 59, 66 , and 68) and other low-risk HPV genotypes.

Cytologic smear specimens were prepared using a customized liquid-based cytology method-the ThinPrep Pap system-according to the manufacturer's protocol (Hologic, MA, USA). The cytologic diagnoses were evaluated by two or more academic cytopathologists in accordance with the Bethesda 2001 criteria[22].

Patients found positive for either cytology (threshold $\geq$ ASC-US \pm hrHPV positive) or HPV16/18 would undergo colposcopy. Some patients with normal cytology or HPV testing but with suspected clinical history and signs were also referred for colposcopy. Multiple focal biopsies and/or endocervical curettage (ECC) were taken from abnormal areas of the cervix during colposcopic examinations[23]. Histologic diagnosis was confirmed by two or more pathologists. If there were results of conization or surgical histopathology inconsistent with the biopsy histopathology, the more severe result was considered as the final diagnosis. 


\section{DNA isolation, DNA bisulfite modification, and quantitative methylation-specific PCR (qMS-PCR)}

Genomic DNA from cervical scraping samples was extracted using a magnetic-bead-based DNA extraction kit (GenePhar Technologies Inc. China) and ctDNA samples in plasma were extracted using Nucleic Acid Purification/Magnetic Beads Kit (GeneShine Biotechnology company, Shanghai, China) following the manufacturer's recommendations. The extracted DNA was treated with bisulphite to convert unmethylated cytosine to uracil using the GS DNA Methylation Kit (GeneShine Biotechnology, China) according to the manufacturer's recommendations. The bisulphite-converted DNA was immediately used as a template for DNA methylation analysis.

The methylation queried in this study mapped upstream to 225-305 bp of the first exon of the Septin 9 transcript isoform v2 (GenBank Access no. NM_001113493.1). The sequences of both primers and probes included $\mathrm{CpG}$ dinucleotides that can differentiate methylated from non-methylated DNA template. The following primer sequences were used for Septin9: forward primer, 5'-TTTAGTTAGCGCGTAGGGTTC3'; reverse primer, 5'-AACTAATAAACAACGAATCGCG' (PCR product, $81 \mathrm{bp}$ ); probe sequence, 5'-FAMACGCCCCCGACGAAACC-BHQ1-3'. The ACTB gene was used as the internal control, with forward primer, 5'-ATAATAAAAAGGAGGTTGGAT-3', and reverse primer, 5'-CTCCCRCAAAACAACCAC-3', and the probe sequence was 5'-VIC-CCACCTTACCCTAAACACTACAAC-BHQ1-3'.

DNA samples from cervical cancer tissues, normal peripheral blood, and double-distilled water (ddH2O) were used as the positive control, negative control, and blank control, respectively. Amplification reactions were performed in triplicate in a total volume of $20 \mu \mathrm{l}$ that consisted of $10 \mu \mathrm{l}$ of $2 \times$ Premix Type reagent, $3 \mu \mathrm{l}$ of bisulfite-converted DNA sample, $0.2 \mu \mathrm{l}$ of $50 \times$ Rox Reference Dye II reagent, $0.5 \mu \mathrm{l}$ of each forward and reverse primer for Septin 9 and ACTB, and $0.8 \mu$ of each probe of Septin9 and ACTB, with a final addition of distilled water to $20 \mu \mathrm{l}$. The qMS-PCR was performed using an ABI 7500 PCR System (Life Technologies, USA) in a 96-well plate. Amplification was carried out by hot-start activation at $94^{\circ} \mathrm{C}$ for $10 \mathrm{~min}$, followed by 50 cycles of denaturation at $93^{\circ} \mathrm{C}$ for $30 \mathrm{~s}$, annealing at $56^{\circ} \mathrm{C}$ for $60 \mathrm{~s}$ and extension at $65^{\circ} \mathrm{C}$ for $30 \mathrm{~s}$, with a final hold at $12{ }^{\circ} \mathrm{C}$. Amplification results were determined by collecting the fluorescent signal to obtain the circulating threshold value(CT value) and the amplification curve of ACTB and Septin9. (Amplification curve in Fig. 2) All samples had a CT value $<32$ for ACTB to assure good sample quality. Signal was defined as positive for Septin9 methylation if both two tests were positive among three repeated trials according to the amplification curve. Samples with a CT value $>45$ for Septin9 were considered as negative results.

\section{Statistical analyses}

All statistical analyses were two-tailed and performed using IBM SPSS Statistics Version 23 (IBM Corp, Armonk, NY, USA). Normally distributed continuous variables are presented as means $\pm S D$, while nonnormally distributed variables are presented as medians $\left(\mathrm{P} \frac{1}{4}-\mathrm{P} \frac{3}{4}\right)$. The Kruskal-Wallis H Test and Loading [MathJax]/jax/output/CommonHTML/fonts/TeX/fontdata.js 
Mann-Whitney $\mathrm{U}$ tests were used for continuous variables to calculate the differences in methylation scores between multiple categories and two categories, respectively. Chi-square tests (including correction for continuity and Fisher's exact-probability test) with a Bonferroni correction were used for categorical variables. The Cochran-Armitage trend test was used to analyze the linear correlation between cervical lesions and Septin9 methylation, and logistic regression was used to analyze the relationship between independent variables and dependent variables. Receiver operating characteristics (ROC) analysis and area under the curve (AUC) - with corresponding 95\% Wald confidence intervals $(95 \% \mathrm{Cl})$ of methylated Septin9- were performed using SPSS and Medcalc software Version 18.9.1 (Seoul, Korea). Sensitivity, specificity, positive predictive value (PPV), negative predictive value (NPV), and Youden Index (YI) were calculated together with their corresponding $95 \% \mathrm{Cls}$, for outcomes of $\geq \mathrm{HSIL}$, and cervical cancer. P-values $<0.05$ were considered statistically significant for all statistical methods.

\section{Results}

\section{Comparison of Septin9 methylation in cervical scrapings with different severity of cervical lesions}

In fresh tissue specimens, the methylation rates of Septin9 in cervical cancer tissues (8/8) were significantly higher than those for cervicitis tissues $(0 / 9)(100 \%$ vs $0 \%, \mathrm{P}<0.0001)$.

In cervical scraping samples, the Cochran-Armitage trend test showed there was a linear trend between cervical lesions and Septin9 methylation. We found Septin9 showed a clear tendency to increase methylation frequency according to the grade of cervical lesion (Cochran-Armitage trend test, $P<0.0001$ ), with $14.81 \%$ (8/54), 25.00\% (13/52), 48.00\% (36/75), and 95.52\% (64/67) in the no-CIN, LSIL, HSIL, and cervical cancer groups, respectively (Table 1 ). 
Table 1

Comparison of Septin9 methylation with different severity of cervical lesions

\begin{tabular}{lllll}
$\begin{array}{l}\text { Histological } \\
\text { category }\end{array}$ & $\begin{array}{l}\text { Methylation scores median } \\
\left.\mathbf{P} \frac{1}{4}-\mathbf{P} \frac{3}{4}\right)\end{array}$ & $\begin{array}{l}\text { Frequency of Septin9 } \\
\text { methylation (\%) }\end{array}$ & $\mathbf{X}$ & $\mathbf{P}$ * \\
\hline Cervical cancer & $14.07(5.52-29.32)$ & $95.52(64 / 67)$ & \\
\hline HSIL a $^{1.77 \times 10^{-2}\left(4.00 \times 10^{-4}-\right.}$ & $48.00(36 / 75)$ & 95.31 & $1.585 \times$ \\
& $3.33)$ & & $10^{-20}$ \\
\hline LSIL $^{\text {b,d }}$ & $\begin{array}{l}1.40 \times 10^{-3}\left(3.00 \times 10^{-4}-1.52\right. \\
\left.\times 10^{-2}\right)\end{array}$ & $25.00(13 / 52)$ & \\
\hline No-CIN c,e,f & $\begin{array}{l}1.00 \times 10^{-3}\left(4.00 \times 10^{-4}-6.20\right. \\
\left.\times 10^{-3}\right)\end{array}$ & $14.81(8 / 54)$ &
\end{tabular}

Septin9 methylation scores were calculated using the following formula: $2[\mathrm{Ct}$ (ACTB) -Ct (Septin9)] $\times$ 100.

Frequency of Septin9 methylation were used to calculate the statistical difference:

$P^{*}<0.0001$, Pearson Chi-square Test

a: compared with cervical cancer, $\chi 2=38.37, P<0.0001$, Pearson Chi-square Test

b: compared with cervical cancer, $\chi 2=63.80, P<0.0001$, Pearson Chi-square Test

c: compared with cervical cancer, $\chi 2=80.83, P<0.0001$, Pearson Chi-square Test

d: compared with HSIL, $\chi 2=6.86, P \otimes 0.05$, Pearson Chi-square Test

e: compared with HSIL, $\chi 2=15.38, \mathrm{P}<0.0001$, Pearson Chi-square Test

f: compared with LSIL, $\chi 2=1.17, P \Downarrow 0.05$, Pearson Chi-square Test

$\mathrm{P}=$ percentiles

The median methylation scores of the four groups tested were $1.00 \times 10^{-3}, 1.40 \times 10^{-3}, 1.77 \times 10^{-2}$, and 14.07, in no-CIN, LSIL, HSIL, and cervical cancer samples, respectively, with significant statistical differences across the four groups $(P<0.0001)$. In pairwise comparisons between groups, the median methylation scores of Septin9 in the HSIL, LSIL, and no-CIN groups were all lower when compared with the cervical cancer group $(P<0.0001)$; the median methylation scores of the HSIL group were also higher than those of the no-CIN group $(P<0.05)$. However, there was no difference in methylation levels between the LSIL group and no-CIN controls, or between LSIL and HSIL groups $(P>0.05)$ (Table 1; Fig. 3 ).

2. Clinical performance indicators of Septin9 methylation, cytology (threshold $\geq$ ASC-US), and HPV16/18 genotyping for discrimination of cervical cancer and $\geq$ HSIL. 
With respect to detecting cervical cancer, Septin9 methylation had a similiar sensitivity of $95.52 \%$ with any of the other testing methods, retaining the highest specificity of $68.51 \%$. ROC curve analysis manifested the optimal AUC of 0.92 for Septin9 methylation in the detection of cervical cancer, with satisfactory NPV, PPV, and YI. (Fig. 4A; Table 2) 
Table 2

Power of Septin9 methylation, cytology and HPV16/18 genotypin for detection $\geq$ HSIL and cervical cancer

\begin{tabular}{|c|c|c|c|c|c|c|c|}
\hline Triage & Endpoint & $\begin{array}{l}\text { AUC } \\
(95 \% \mathrm{Cl})\end{array}$ & $\begin{array}{l}\text { Sensitivity(\%) } \\
(95 \% \mathrm{Cl})\end{array}$ & $\begin{array}{l}\text { Specificity(\%) } \\
(95 \% \mathrm{Cl})\end{array}$ & $\begin{array}{l}\text { PPV(\%) } \\
(95 \% \mathrm{Cl})\end{array}$ & $\begin{array}{l}\text { NPV(\%) } \\
(95 \% \mathrm{Cl})\end{array}$ & $\begin{array}{l}Y I \\
(\%)\end{array}$ \\
\hline \multirow[t]{2}{*}{$\begin{array}{l}\text { Septing } \\
\text { methylation }\end{array}$} & $\geq$ HSIL & $\begin{array}{l}0.80 \\
(0.74- \\
0.86)\end{array}$ & $\begin{array}{l}70.42(0.63- \\
0.78)\end{array}$ & $\begin{array}{l}80.19(0.73- \\
0.88)\end{array}$ & $\begin{array}{l}82.64 \\
(0.75- \\
0.88)\end{array}$ & $\begin{array}{l}66.93 \\
(0.58- \\
0.75)\end{array}$ & 50.61 \\
\hline & $\begin{array}{l}\text { Cervical } \\
\text { cancer }\end{array}$ & $\begin{array}{l}0.92 \\
(0.89- \\
0.96)\end{array}$ & $\begin{array}{l}95.52(0.91- \\
1.00)\end{array}$ & $\begin{array}{l}68.51(0.62- \\
0.75)\end{array}$ & $\begin{array}{l}52.89 \\
(0.44- \\
0.62)\end{array}$ & $\begin{array}{l}97.64 \\
(0.93- \\
0.99)\end{array}$ & 64.03 \\
\hline \multirow[t]{2}{*}{$\begin{array}{l}\text { Cytology } \\
\text { ( } \geq \text { ASC-US) }\end{array}$} & $\geq$ HSIL & $\begin{array}{l}0.71 \mathrm{a} \\
(0.64- \\
0.78)\end{array}$ & $\begin{array}{l}90.14 \mathrm{c} \\
(0.85-0.95)\end{array}$ & $\begin{array}{l}51.89 \mathrm{~d} \\
(0.42-0.61)\end{array}$ & $\begin{array}{l}71.51 \\
(0.65- \\
0.78)\end{array}$ & $\begin{array}{l}79.71 \\
(0.69- \\
0.88)\end{array}$ & 42.03 \\
\hline & $\begin{array}{l}\text { Cervical } \\
\text { cancer }\end{array}$ & $\begin{array}{l}0.67 \mathrm{~b} \\
(0.60- \\
0.74)\end{array}$ & $\begin{array}{l}97.01 * \\
(0.93-1.01)\end{array}$ & $\begin{array}{l}37.02 \mathrm{e} \\
(0.30-0.44)\end{array}$ & $\begin{array}{l}36.31 \\
(0.30- \\
0.44)\end{array}$ & $\begin{array}{l}97.10 \\
(0.90- \\
0.99)\end{array}$ & 34.03 \\
\hline \multirow[t]{2}{*}{$\begin{array}{l}\text { HPV16/18 } \\
\text { genotyping }\end{array}$} & $\geq$ HSIL & $\begin{array}{l}0.68 \mathrm{a} \\
(0.61- \\
0.75)\end{array}$ & $\begin{array}{l}62.68 * \\
(0.55-0.71)\end{array}$ & $\begin{array}{l}73.58 * \star \\
(0.65-0.82)\end{array}$ & $\begin{array}{l}76.07 \\
(0.68- \\
0.83)\end{array}$ & $\begin{array}{l}59.54 \\
(50.98- \\
67.56)\end{array}$ & 36.26 \\
\hline & $\begin{array}{l}\text { Cervical } \\
\text { cancer }\end{array}$ & $\begin{array}{l}0.74 \mathrm{~b} \\
(0.67- \\
0.81)\end{array}$ & $\begin{array}{l}82.09 * \\
(72.91- \\
91.27)\end{array}$ & $\begin{array}{l}65.75 \star \star \\
(0.59-0.73)\end{array}$ & $\begin{array}{l}47.01 \\
(0.38- \\
0.56)\end{array}$ & $\begin{array}{l}90.84 \\
(0.85- \\
0.95)\end{array}$ & 47.83 \\
\hline \multirow[t]{2}{*}{$\begin{array}{l}\text { HPV16/18 } \\
\text { or Septin9 } \\
\text { methylation }\end{array}$} & $\geq$ HSIL & $\begin{array}{l}0.71 a \\
(0.65- \\
0.78)\end{array}$ & $\begin{array}{l}82.39 \mathrm{c} \\
(0.76-0.89)\end{array}$ & $\begin{array}{l}60.38 \mathrm{~d} \\
(0.51-0.70)\end{array}$ & $\begin{array}{l}73.58 \\
(0.66- \\
0.80)\end{array}$ & $\begin{array}{l}71.91 \\
(0.62- \\
0.80)\end{array}$ & 42.77 \\
\hline & $\begin{array}{l}\text { Cervical } \\
\text { cancer }\end{array}$ & $\begin{array}{l}0.74 \mathrm{~b} \\
(0.68- \\
0.80)\end{array}$ & $\begin{array}{l}98.51 * \\
(0.96-1.01)\end{array}$ & $\begin{array}{l}48.62 \mathrm{e} \\
(0.41-0.56)\end{array}$ & $\begin{array}{l}41.51 \\
(0.34- \\
0.49)\end{array}$ & $\begin{array}{l}98.88 \\
(0.94- \\
1.00)\end{array}$ & 47.13 \\
\hline \multicolumn{8}{|c|}{$A \cup C=$ area under curve; $Y I=$ youden index } \\
\hline \multicolumn{8}{|c|}{ * compared with the sensitivity of Septin9 methylation in group of $\geq \mathrm{HSIL}$ and cervical cancer, $\mathrm{P} \bowtie 0.05$} \\
\hline \multicolumn{8}{|c|}{$\begin{array}{l}\star * \text { compared with the specificity of Septin } 9 \text { methylation in group of } \geq \mathrm{HSIL} \text { and cervical cancer, } \\
\mathrm{P} \otimes 0.05\end{array}$} \\
\hline \multicolumn{8}{|c|}{ a: compared with the AUC of Septin9 methylation in group of $\geq \mathrm{HSIL}, \mathrm{P}<0.05$} \\
\hline \multicolumn{8}{|c|}{ b: compared with the AUC of Septin9 methylation in group of cervical cancer, $\mathrm{P} \otimes 0.05$} \\
\hline \multicolumn{8}{|c|}{ c: compared with the sensitivity of Septin9 methylation in group of $\geq \mathrm{HSIL}, \mathrm{P} \otimes 0.05$} \\
\hline \multicolumn{8}{|c|}{ d: compared with the specificity of Septin9 methylation in group of $\geq$ HSIL, P $₫ 0.05$} \\
\hline e: compared & th the spec & icity of $\mathrm{S}$ & tin9 methylatic & in group of cer & sal cance & $₫ 0.05$ & \\
\hline
\end{tabular}


Regarding the detection of $\geq \mathrm{HSIL}$, although the sensitivity of Septin9 methylation analysis was slightly lower relative to cytologic testing $(70.42 \%$ vs $90.14 \%, P<0.05)$, the specificity was significantly higher $(80.19 \%$ vs $51.89 \%, \mathrm{P}<0.05)$. Testing for methylated Septin9 also had a relatively lower sensitivity but higher specificity than combined tests for Septin9 methylation with HPV16/18 genotyping $(P<0.05)$, for distinguishing $\geq$ HSIL from $\leq$ LSIL. In addition, analysis of Septin9 methylation demonstrated a satisfactory PPV and YI in the detection of $\geq$ HSIL than any other test. ROC curve analysis revealed that Septin9 methylation exhibited a strong diagnostic accuracy in discriminating $\geq$ HSIL from $\leq$ LSIL, with the highest AUC of 0.80 , and a sensitivity of $70.42 \%$ and specificity of $80.19 \%$. (Fig. 4B; Table 2)

3. Relationship between pelvic nodal metastasis of cervical cancer and Septin9 methylation in ctDNA from cervical cancer plasma

Of the 113 cervical cancer specimens, 32 patients were positive for pelvic lymph nodes $(\operatorname{LN}(+))$ and 81 were negative for pelvic lymph nodes $(\mathrm{LN}(-))$ as confirmed by postoperative histopathology. The average age of the 113 patients with cervical cancer was 48.08 years; and neither age, pathological type, nor tumor size affected the status of pelvic nodal metastasis $(P>0.05)$. However, cervical cancer stage was associated with pelvic nodal metastasis, and locally advanced cervical cancer (IB2 or above) was more prone to metastasis $(P<0.05)$. (Table 3$)$ 
Table 3

Relationship between clinicopathological features of 113 cervical cancer and status of pelvic lymph node metastasis

\begin{tabular}{|c|c|c|c|c|}
\hline Characteristics & $\mathrm{n} / \mathrm{N}$ & $\begin{array}{l}\text { Frequency of pelvic LN metastasis } \\
(\%)\end{array}$ & $x^{2}$ & $\mathbf{P}$ \\
\hline \multicolumn{5}{|c|}{$\begin{array}{l}\text { Age (average } 48.0796 \pm \\
10.009)\end{array}$} \\
\hline$\leq 48$ & $12 / 48$ & 25.00 & 0.45 & 0.501 * \\
\hline$\varangle 48$ & $20 / 65$ & 30.77 & & \\
\hline \multicolumn{5}{|l|}{ Histology } \\
\hline SCC & $28 / 99$ & 28.28 & 0.00 & 1.000 ** \\
\hline Non-SCC & $4 / 14$ & 28.57 & & \\
\hline \multicolumn{5}{|l|}{ Stage } \\
\hline IA or IB1 & $12 / 62$ & 19.35 & 5.44 & $\underset{\star \star \star *}{0.020}$ \\
\hline IB2 or above & $20 / 51$ & 39.22 & & \\
\hline \multicolumn{5}{|l|}{ Size } \\
\hline$\leq 4$ & $21 / 84$ & 25.00 & 1.78 & 0.183 * \\
\hline$\nabla 4$ & $11 / 29$ & 37.93 & & \\
\hline \multicolumn{5}{|c|}{$\mathrm{n}$ : the number of patients with pelvic lymph node metastasis; $\mathrm{N}$ : the number of total patients } \\
\hline \multicolumn{5}{|c|}{ SCC = squamous cell carcinoma } \\
\hline \multicolumn{5}{|c|}{ * Pearson Chi-square Test, P『0.05; } \\
\hline \multicolumn{5}{|c|}{ ** Correction for continuity Test, $\mathrm{P} \otimes 0.05$; } \\
\hline
\end{tabular}

We first defined $>1.5 \mathrm{ng} / \mathrm{ml}$ as positive for SCC-Ag based on the laboratory of the Guangdong Children and Women Hospital. Our study found no significant difference in the positive rates of SCC-Ag (threshold, $1.5 \mathrm{ng} / \mathrm{ml})$ between the $\mathrm{LN}(+)$ and $\mathrm{LN}(-)$ groups $(65.62 \%$ vs $53.09 \%, P>0.05)$. However, the Septin9 methylation frequency in the $L N(+)$ group was higher than in the $L N(-)$ group $(50 \%$ vs $18.52 \%, P<0.05)$. (Table 4) 
Table 4

Relationship between status of pelvic nodal metastasis and Septin9 methylation in ctDNA from 113 cervical cancer plasma

\begin{tabular}{|llll|}
\hline Clinical Parameters & LN(+) & LN(-) & P \\
\hline Frequency of Septin9 methylation (\%) & $50.00(16 / 32)$ & $18.52(15 / 81)$ & $0.001^{\text {a }}$ \\
\hline Frequency of SCC-Ag (\%) (threshold 1.5 ng/ml) & $65.62(21 / 32)$ & $53.09(43 / 81)$ & $0.226^{\text {b }}$ \\
\hline
\end{tabular}

$\mathrm{SD}=$ Standard Deviation; $\mathrm{P}=$ Percentiles $; \mathrm{SCC}-\mathrm{Ag}=$ squamous cell carcinoma antigen; $\mathrm{LN}(+)=$ positive for pelvic lymph node; $\mathrm{LN}(-)$ = negative for pelvic lymph node

a: Pearson Chi-squared Test, $\chi 2=11.42, \mathrm{P} \otimes 0.05$;

b: Pearson Chi-squared Test, $\chi 2=1.47, \mathrm{P} \otimes 0.05$.

When we evaluated the effects of Septin9 methylation and SCC-Ag on the status of pelvic nodal metastasis by logistic regression analysis, we found that the regression model was statistically significant. When two independent variables, such as SCC-Ag (positive or negative) and Septin9 methylation (yes or no) included, only Septin9 methylation status was found to be meaningful for the prediction of pelvic nodal metastasis. The OR value suggested that the risk of pelvic nodal metastasis in patients with methylated Septin9 was 4.193 times $(95 \% \mathrm{Cl}, 2.27-12.85)$ than that without methylation ( $\mathrm{P}$ $<0.05)$.

Septin9 methylation possessed a sensitivity equal to that of SCC-Ag in predicting pelvic nodal metastasis ( $50.00 \%$ vs $65.63 \%, P>0.05)$, but a higher specificity $(81.48 \%$ vs $46.91 \%, P<0.05)$. A co-test of methylated Septin9 with SCC-Ag was utilized to improve the sensitivity in differentiating $\mathrm{LN}(+)$ patients from $L N(-)$ patients, and we acquired an increasing sensitivity from $50 \%$ to nearly $80 \%$. In addition, Septin9 methylation was also equivalent to an AUC of 0.66 when comparing all the three testing $(P>$ 0.05). (Table 5) 
Table 5

Power of Septin9 methylation in plasma and SCC-Ag for prediction of pelvic nodal metastasis

\begin{tabular}{|c|c|c|c|c|c|}
\hline Category & $\begin{array}{l}\text { AUC } \\
(95 \% \mathrm{Cl})\end{array}$ & $\begin{array}{l}\text { Sensitivity (\%) } \\
(95 \% \mathrm{Cl})\end{array}$ & $\begin{array}{l}\text { Specificity (\%) } \\
(95 \% \mathrm{Cl})\end{array}$ & $\begin{array}{l}\text { PPV (\%) } \\
\text { (95\% Cl) }\end{array}$ & $\begin{array}{l}\text { NPV (\%) } \\
(95 \% \mathrm{Cl})\end{array}$ \\
\hline $\begin{array}{l}\text { Septin9 methylation } \\
\text { (yes or no) }\end{array}$ & $\begin{array}{l}0.66 \\
(0.54- \\
0.78)\end{array}$ & $\begin{array}{l}50.00(0.33- \\
0.67)\end{array}$ & $\begin{array}{l}81.48(0.73- \\
0.90)\end{array}$ & $\begin{array}{l}51.61 \\
(0.35- \\
0.68)\end{array}$ & $\begin{array}{l}80.49 \\
(0.71- \\
0.88)\end{array}$ \\
\hline $\begin{array}{l}\text { SCC-Ag (positive or } \\
\text { negative) }\end{array}$ & $\begin{array}{l}0.56 \text { * } \\
(0.45- \\
0.68)\end{array}$ & 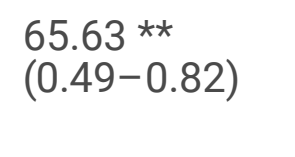 & $\begin{array}{l}46.91 \star \star \star \star \\
(0.36-0.58)\end{array}$ & $\begin{array}{l}32.81 \\
(0.23- \\
0.45)\end{array}$ & $\begin{array}{l}77.55 \\
(0.64- \\
0.87)\end{array}$ \\
\hline $\begin{array}{l}\text { SCC-Ag or Septin9 } \\
\text { methylation }\end{array}$ & $\begin{array}{l}0.61 * \\
(0.50- \\
0.72)\end{array}$ & $\begin{array}{l}78.13 \star \star \star \\
(0.64-0.92)\end{array}$ & $\begin{array}{l}43.21 \star \star \star \star \\
(0.32-0.54)\end{array}$ & $\begin{array}{l}35.21 \\
(0.25- \\
0.47)\end{array}$ & $\begin{array}{l}83.33 \\
(0.70- \\
0.92)\end{array}$ \\
\hline \multicolumn{6}{|c|}{ *: compared with Septin9 methylation, $\mathrm{P} \otimes 0.05$} \\
\hline \multicolumn{6}{|c|}{$\star \star$ : compared with the sensitivity of Septin9 methylation, $\mathrm{P} \otimes 0.05$} \\
\hline \multicolumn{6}{|c|}{$\star \star \star$ : compared with the sensitivity of Septin 9 methylation, $\mathrm{P} \otimes 0.05$} \\
\hline
\end{tabular}

\section{Discussion}

Septin9 is a novel tumor biomarker and a member of the Septin gene family involved in cell division, migration, apoptosis and DNA repair[24]. Studies have shown that Septin9 produces multiple tissuespecific isoforms that possesses various functions and plays different roles in different tissues[25]. For example, Connolly et al. proved that methylated Septin9-v3 was associated with the occurrence of breast cancer[15], and other evidences showed Septin9-v2 also to be a novel biomarker for the detection of breast cancer[26]. A very recent study found that Septin9 was hypermethylated in cervical cancer tissues compared to the normal controls, with satisfatory sensitivity and specificity[20]. However, the feasibility of detecting Septin9 methylation in cervical scrapings has not yet been carried out. Our team previously established a high-quality qMS-PCR methylation method for non-invasive screening of colorectal cancer. In our pilot study, we also found Septin9 transcript isoform v2 was highly methylated in cervical cancer tissues, whereas no methylation in cervicitis controls. We further confirmed that in cervical scrapings, increases in Septin9 methylation were significantly correlated with greater severity of cervical lesions, which was consistent with Jiao's recent report[20]. Strangely, approximately 15\% Septin9 methylation were detected in the no-CIN lesion group of scrapings, while no Septin9 methylation was detected in fresh cervicitis tissue. We conjectured the reason for this difference in different specimen source was that the cervical scraping samples were infected with HPV, whereas the fresh cervicitis tissue was negative for HPV. Because HPV infection was a prerequisite for cervical cancer[2, 27]; DNA methylation was an early event of cancer, and studies had shown that methylation was closely related to cervical cancer development[28-29]. Therefore, in cervical scrapings with HPV infection, there might be patients with 
potential cervical lesions, resulting in almost $15 \%$ detection rates of methylation in the no-CIN cervical scrapings.

This study revealed a slightly poor sensitivity of methylated Septin9 in identifying $\geq$ HSIL than cytologic testing ( $\geq$ ASC-US) $(70.42 \%$ vs $90.14 \%)$, while displayed a superior specificity $(80.19 \%$ vs $51.89 \%)$, with a correspondingly equivalent AUC ( 0.80 vs 0.71$)$. These data were similar with our previous work that methylated FAM19A4 had a lower sensitivity but higher specificity than cytologic testing in detecting $\geq$ HSIL[21]. On the contrary, methylated Septin9 showed advantages in detection of cervical cancer, achieving a better sensitivity of $95.52 \%$ and a specificity of $68.51 \%$, with an AUC of 0.92 , than cytologic testing ( $\geq$ ASC-US) and HPV16/18 genotyping. It could be seen that the detection rates of Septin9 methylation in cervical cancer was high, but in $\geq \mathrm{HSIL}$ was not as good as cytological testing. The detection rate of Septin9 methylation in cervical cancer was as high as $95.52 \%$, while $70.42 \%$ in $\geq \mathrm{HSIL}$, and only about $50 \%$ in HSIL alone detection. Because methylation occurred early in the course of cancer, the reduction of Septin9 methylation in HSIL indicated that most HSIL lesions progressed to cancer, and a small proportion of them would regress eventually. This phenomenon was in accordance with previous studies that a subset of HSIL lesions about $30 \%$ will progresses to cervical cancer[30]. Another evident also suggested that $50 \%$ of the HSIL patients would progressed cancer within 30 years, only if they had persistent disease within 24 months after their biopsy[31]. All these evidences supposed that $50 \%$ patients with Septin9 methylation in HSIL may developed higher risk of cervical cancer. However, what we did was a retrospective study that showed a static data. Additionally, our study was unable to further track the risk of progression to cancer in HSIL patients with or without methylation, because of intervention of surgery according to current guideline. However, some studies have shown that patients with methylation have a worse prognosis. A long-term follow-up study indicated that the cervical cells showing FAM19A4/mir124-2 methylation had a remarkable tendency to progress to cancer after 5 years, even if they were not cancerous at the time of sample collection[32]. A review also raised an argument that an absence of methylation in HSIL did not progress, which would revolutionize the management strategies of cervical cancer if this assumption was true[33]. In brief, although Septin9 methylation showed a slightly poorer sensitivity in detecting $\geq \mathrm{HSIL}$, it still played an indispensable role in detecting cervical cancer. Septin9 methylation testing can reduce the rates of excessive colposcopy referral and over-diagnosis in clinical application; and improve the accuracy of detection rates of cervical lesions for its high specificity.

We also herein explored for the first time the role of methylated Septin9 in plasma for the prediction of pelvic nodal metastasis of cervical cancer. Some studies have depicted a 5-year survival rate for patients without lymph node metastasis of $85-90 \%$, which then declined to $50-55 \%$ with lymph node metastasis, suggesting a vital role for the latter in the prognosis of cervical cancer[34]. Preoperative magnetic resonance(MR) examination was often used to determine the presence of pelvic metastatic lymph nodes for cervical cancer, and the criteria for MR diagnosis was the maximal axial diameter of more than $10 \mathrm{~mm}$. However, reviews displayed a varying sensitivity of $0.38-0.89$ and specificity of $0.78-0.99$ for MR imaging[35], and MR imaging technology was expensive and patients with MR contraindications Loading [MathJax]/jax/output/CommonHTML/fonts/TeX/fontdata.js shifted to the application of serum-based 
biomarkers recently. The serum-based protein biomarker SCC-Ag has been commonly used for evaluating the status and prognosis of cervical cancer, whereas such proteins can also be found at low concentrations in individuals without cancer[36]. Nevertheless, tumor markers in ctDNA do not occur in non-neoplastic diseases, and higher levels of ctDNA can be detected in over $80 \%$ of metastatic tumorsmore than is observed for most conventional biomarkers[37-38]. Therefore, plasma-based ctDNA detection as a non-invasive examination of solid tumors (termed "liquid-biopsy") has provided an alternative to tissue-biopsy, reducing the pain, risk, and expense caused by tissue biopsy.

Our study revealed that both Septin9 methylation and SCC-Ag effectively reflected the status of lymph node metastasis of cervical cancer. Furthermore, we calculated the optimal SCC-Ag threshold $(3.8 \mathrm{ng} / \mathrm{ml})$ to predict the status of pelvic nodal metastasis, consistent with the findings by Takeshima[39] and $\mathrm{Xu}[40]$ where the optimal SCC-Ag thresholds were $4 \mathrm{ng} / \mathrm{mL}$ and $3.26 \mathrm{ng} / \mathrm{mL}$. Although Septin 9 methylation was less sensitive than SCC-Ag, the former manifested the greatest specificity at $81.48 \%$ and a PPV of $51.61 \%$, which would predict nodal metastasis more accurately. In addition, we also demonstrated that the co-test of methylated Septin9 and SCC-Ag was more sensitive in the identification of lymph node metastasis. Lee et al[41] evaluated a combination test of CEA, CA19-9, and Septin9 methylation and achieved a higher sensitivity and specificity than with any single marker. Plasma-based methylated Septin9 was also suggested to be a predictive tool in individuals unable or unwilling to undergo standard radical surgery. In clinical application, the satisfactory specificity of methylated Septin9 made it an accurate and reliable method of defining patients at high risk for pelvic lymphatic metastasis. When SCCAg was coupled to Septin9 methylation, the combination was more sensitive in recognizing lymph node metastasis.

\section{Conclusions}

We herein report the relationship between Septin9 methylation and cervical cancer. In addition, we are the first to apply a plasma-based Septin 9 methylation as a biomarker to predict pelvic nodal metastasis of cervical cancer, providing a foundation for the future development of non-invasive follow-up of cervical cancer. Nevertheless, there is a limitation of this study that this is a retrospective study, and the relative scarcity of long-term follow-up data makes untenable the analysis of methylated Septin9 in predicting progression of benign cervical lesions to cervical cancer. Thus, a larger number of specimens, follow-up analysis, and prospective experiments are required to verify the prognostic performance of Septin 9 methylation.

\section{Abbreviations}

qMS-PCR:quantitative methylation-specific PCR; hrHPV: high risk human papillomavirus; ctDNA:circulating tumor DNA; CIN:cervical intraepithelial neoplasia; $\geq C I N \rrbracket: C I N \rrbracket$ or cervical cancer; $\geq$ CIN』:CIN』 or other aforementioned lesions; ASC-US:atypical squamous-cells of undetermined significance; LSIL:low-grade squamous intraepithelial lesion; HSIL:high-grade squamous intraepithelial or cervical cancer; AUC:area under the curve; 
ROC:Receiver operating characteristics; PPV:positive predictive value; NPV:negative predictive value; YI:Youden Index; ECC:endocervical curettage; SCC-Ag:squamous-cell carcinoma-antigen; LN:lymph nodes.

\section{Declarations}

Acknowledgments: We thank all the participants who took part in these trials and contributed to this research. We thank GeneShine Biotechnology in China for the help of qMS-PCR detection technology. We thank LetPub (www.letpub.com) for its linguistic assistance during the preparation of this manuscript. This research was supported by the Research of DNA methylation in cervical cells for the triage of patients with HPV16/18 infection in cervical cancer screening,Guangdong Provincial Technology Project(2017ZC0317. The authors declare no potential conflicts of interest.

\section{Author's contributions}

$Z L, X P L, J M$ and WPZ were at the origin of the conception and direct the progress of the study. QWB read the relevant literatures, performed the statistical analyses, and wrote the manuscript. HYW read the relevant literatures and drafted the manuscript. SFW, JM, YHL, HD and WL were involved in the conception, design of the study, interpretation of results and helped to revise the manuscript. LLH, JQL and HPL participated to collect specimens and do the experiment. All authors read and approved the final manuscript.

\section{Funding}

This research was supported by Research of DNA methylation in cervical cells for the triage of patients with HPV16/18 infection in cervical cancer screening, Guangdong Provincial Technology Project (No.2017ZC0317》

\section{Availability of data and materials}

All analysed data during this study are included in this published article and its Additional information files.

\section{Ethics approval and consent to participate}

This study was approved by Guangdong Women and Children Hospital Ethics Committee(reference number: 201901018). And all participants provided written informed consent before specimens collection, according to institutional guidelines in this research.

\section{Consent for publication}

Not applicable.

\section{Competing interests}


The authors declare that they have no competing of interests.

\section{Author details}

${ }^{a}$ Department of Gynecology, Guangdong Women and Children Hospital, Guangzhou, China

${ }^{b}$ Translational medicine center; Guangdong Women and Children Hospital, Guangzhou, China

${ }^{*}$ Corresponding authors:

Translational medicine center, Guangdong Women and Children Hospital, 521 Xing Nan Road, Guangzhou 511400, China. E-mail address: zhangliang1999@tsinghua.org.cn (L. Zhang).

Department of Gynecology, Guangdong Women and Children Hospital, 521 Xing Nan Road, Guangzhou 511400, China. E-mail address: 2488692399@qq.com (X. Luo).

\section{References}

1. Bray F, Ferlay J, Soerjomataram I, Siegel RL, Torre LA, Jemal A. Global cancer statistics 2018: GLOBOCAN estimates of incidence and mortality worldwide for 36 cancers in 185 countries[J]. Cancer J Clin. 2018;68(6):394-424.

2. Sahasrabuddhe VV, Luhn P, Wentzensen N. Human papillomavirus and cervical cancer: biomarkers for improved prevention efforts. Future microbiology. 2011;6(9):1083-98.

3. Lai HC, Ou YC, Chen TC, Huang HJ, Cheng YM, Chen $\mathrm{CH}$. et al. PAX1/SOX1 DNA methylation and cervical neoplasia detection: a Taiwanese Gynecologic Oncology Group (TGOG) study. Cancer medicine. 2014;3(4):1062-74.

4. Wang KH, Lin CJ, Liu CJ, Liu DW, Huang RL, Ding DC. et al. Global methylation silencing of clustered proto-cadherin genes in cervical cancer: serving as diagnostic markers comparable to HPV. Cancer medicine. 2015;4(1):43-55.

5. De Strooper LM, Meijer CJ, Berkhof J, Hesselink AT, Snijders PJ, Steenbergen RD, et al. Methylation analysis of the FAM19A4 gene in cervical scrapes is highly efficient in detecting cervical carcinomas and advanced CIN2/3 lesions. Cancer prevention research (Philadelphia Pa). 2014;7(12):1251-7.

6. Clarke MA, Luhn P, Gage JC, Bodelon C, Dunn ST, Walker J. et al. Discovery and validation of candidate host DNA methylation markers for detection of cervical precancer and cancer. International journal of cancer. 2017;141(4):701 - 10.

7. Su PH, Lai HC, Huang RL, Chen LY, Wang YC, Wu TI. et al. Paired Box-1 (PAX1) Activates Multiple Phosphatases and Inhibits Kinase Cascades in Cervical Cancer. Scientific reports. 2019;9(1):9195.

8. Cheng-Yen Lai J, Yang MS, Lu KW, Yu L, Liou WZ, Wang KL. The role of sentinel lymph node biopsy in early-stage cervical cancer: A systematic review. Taiwan J Obstet Gynecol. 2018;57(5):627 - 35.

9. Noguchi H, Shiozawa I, Sakai Y, Yamazaki T, Fukuta T. Pelvic lymph node metastasis of uterine 
10. Li D, Cai J, Kuang Y, Cao J, Wang Z. Surgical-pathologic risk factors of pelvic lymph node metastasis in stage Ib1-Ilb cervical cancer. Acta obstetricia et gynecologica Scandinavica. 2012;91(7):802-9.

11. Zhang J, Yao T, Lin Z, Gao Y. Aberrant Methylation of MEG3 Functions as a Potential Plasma-Based Biomarker for Cervical Cancer. Scientific reports. 2017;7(1):6271.

12. Song L, Yu H, Jia J, Li Y. A systematic review of the performance of the SEPT9 gene methylation assay in colorectal cancer screening, monitoring, diagnosis and prognosis[J]. Cancer Biomark A. 2017;18(4):425 - 32.

13. Church TR, Wandell M, Lofton-Day C, Mongin SJ, Burger M, Payne SR. et al. Prospective evaluation of methylated SEPT9 in plasma for detection of asymptomatic colorectal cancer. Gut. 2014;63(2):317 - 25.

14. Nian J, Sun X, Ming S, Yan C, Ma Y, Feng Y. et al. Diagnostic Accuracy of Methylated SEPT9 for Blood-based Colorectal Cancer Detection: A Systematic Review and Meta-Analysis. Clinical translational gastroenterology. 2017;8(1):e216.

15. Connolly D, Yang Z, Castaldi M, Simmons N, Oktay MH, Coniglio S. et al. Septin 9 isoform expression, localization and epigenetic changes during human and mouse breast cancer progression. Breast cancer research: BCR. 2011;13(4):R76.

16. Powrozek T, Krawczyk P, Kucharczyk T, Milanowski J. Septin 9 promoter region methylation in free circulating DNA-potential role in noninvasive diagnosis of lung cancer: preliminary report. Medical oncology (Northwood, London). 2014;31(4):p. 917.

17. Oussalah A, Rischer S, Bensenane M, Conroy G, Filhine-Tresarrieu P, Debard R. et al. Plasma mSEPT9: A Novel Circulating Cell-free DNA-Based Epigenetic Biomarker to Diagnose Hepatocellular Carcinoma. EBioMedicine. 2018;30:138 - 47.

18. Bennett KL, Karpenko M, Lin MT, Claus R, Arab K, Dyckhoff G. et al. Frequently methylated tumor suppressor genes in head and neck squamous cell carcinoma. Cancer research. 2008;68(12):4494-9.

19. Cohen JD, Javed AA, Thoburn C, Wong F, Tie J, Gibbs P. et al. Combined circulating tumor DNA and protein biomarker-based liquid biopsy for the earlier detection of pancreatic cancers. Proc Natl Acad Sci USA. 2017;114(38):10202-7.

20. Jiao X, Zhang S, Jiao J, Zhang T, Qu W, Muloye GM, Kong B, Zhang Q, Cui B. Promoter methylation of SEPT9 as a potential biomarker for early detection of cervical cancer and its overexpression predicts radioresistance. Clinical epigenetics. 2019;11(1):120.

21. Bu Q, Wang S, Ma J, Zhou X, Hu G, Deng H. et al. The clinical significance of FAM19A4 methylation in high-risk HPV-positive cervical samples for the detection of cervical (pre)cancer in Chinese women. BMC Cancer. 2018;18(1):1182.

22. Solomon D, Davey D, Kurman R, Moriarty A, O'Connor D, Prey M. et al. The 2001 Bethesda System: terminology for reporting results of cervical cytology. Jama. 2002;287(16):2114-9.

23. Bornstein J, Bentley J, Bosze P, Girardi F, Haefner H, Menton M. et al. 2011 colposcopic terminology of the International Federation for Cervical Pathology and Colposcopy. Obstetrics gynecology. 
24. Connolly D, Abdesselam I, Verdier-Pinard P, Montagna C. Septin roles in tumorigenesis. Biological chemistry. 2011;392(8-9):725 - 38.

25. Mostowy S, Cossart P. Septins: the fourth component of the cytoskeleton. Nature reviews Molecular cell biology. 2012;13(3):183 - 94.

26. Matsui S, Kagara N, Mishima C, Naoi Y, Shimoda M, Shimomura A. et al. Methylation of the SEPT9_V2 promoter as a novel marker for the detection of circulating tumor DNA in breast cancer patients. Oncol Rep. 2016;36(4):2225-35.

27. Crosbie EJ, Einstein MH, Franceschi S, Kitchener HC. Human papillomavirus and cervical cancer. Lancet. 2013;382(9895):889-99.

28. Feinberg AP, Tycko B. The history of cancer epigenetics. Nature reviews Cancer. 2004;4(2):143 - 53.

29. Yang HJ. Aberrant DNA methylation in cervical carcinogenesis[J]. Chinese journal of cancer. 2013;32(1):42 - 8.

30. Koeneman MM, Kruitwagen RF, Nijman HW, Slangen BF. Van Gorp T, Kruse AJ. Natural history of high-grade cervical intraepithelial neoplasia: a review of prognostic biomarkers. Expert review of molecular diagnostics. 2015;15(4):527 - 46.

31. McCredie MR, Sharples KJ, Paul C, Baranyai J, Medley G, Jones RW. et al. Natural history of cervical neoplasia and risk of invasive cancer in women with cervical intraepithelial neoplasia 3: a retrospective cohort study. The Lancet Oncology. 2008;9(5):425 - 34.

32. De Strooper LMA, Berkhof J, Steenbergen RDM, Lissenberg-Witte BI, Snijders PJF, Meijer C, et al. Cervical cancer risk in HPV-positive women after a negative FAM19A4/mir124-2 methylation test: A post hoc analysis in the POBASCAM trial with 14 year follow-up[J]. Int J Cancer. 2018;143(6):1541-8.

33. Lorincz AT. Virtues and Weaknesses of DNA Methylation as a Test for Cervical Cancer Prevention. Acta cytologica. 2016;60(6):501 - 12.

34. Thaker NG, Klopp AH, Jhingran A, Frumovitz M, lyer RB, Eifel PJ. Survival outcomes for patients with stage IVB vulvar cancer with grossly positive pelvic lymph nodes: time to reconsider the FIGO staging system? Gynecol Oncol. 2015;136(2):269 - 73.

35. Reinhardt MJ, Ehritt-Braun C, Vogelgesang D, Ihling C, Hogerle S, Mix M. et al. Metastatic lymph nodes in patients with cervical cancer: detection with MR imaging and FDG PET[J]. Radiology. 2001;218(3):776- 82.

36. Dasari S, Wudayagiri R, Valluru L. Cervical cancer: Biomarkers for diagnosis and treatment[J]. Clinica chimica acta; international journal of clinical chemistry. 2015;445:7-11.

37. Bettegowda C, Sausen M, Leary RJ, Kinde I, Wang Y, Agrawal N. et al. Detection of circulating tumor DNA in early- and late-stage human malignancies[J]. Science translational medicine. 2014;6(224):224ra24.

38. Diehl F, Li M, Dressman D, He Y, Shen D, Szabo S. et al. Detection and quantification of mutations in the plasma of patients with colorectal tumors[J]. Proc Natl Acad Sci USA. 2005;102(45):16368-73. 
39. Takeshima N, Hirai Y, Katase K, Yano K, Yamauchi K, Hasumi K. The value of squamous cell carcinoma antigen as a predictor of nodal metastasis in cervical cancer[J]. Gynecol Oncol. 1998;68(3):263-6.

40. Xu F, Li Y, Fan L, Ma J, Yu L, Yi H. et al. Preoperative SCC-Ag and thrombocytosis as predictive markers for pelvic lymphatic metastasis of squamous cervical cancer in early FIGO stage[J]. J Cancer. 2018;9(9):1660-6.

41. Lee HS, Hwang SM, Kim TS, Kim DW, Park DJ, Kang SB. et al. Circulating methylated septin 9 nucleic Acid in the plasma of patients with gastrointestinal cancer in the stomach and colon[J]. Translational oncology. 2013;6(3):290-6.

\section{Figures}


(A)

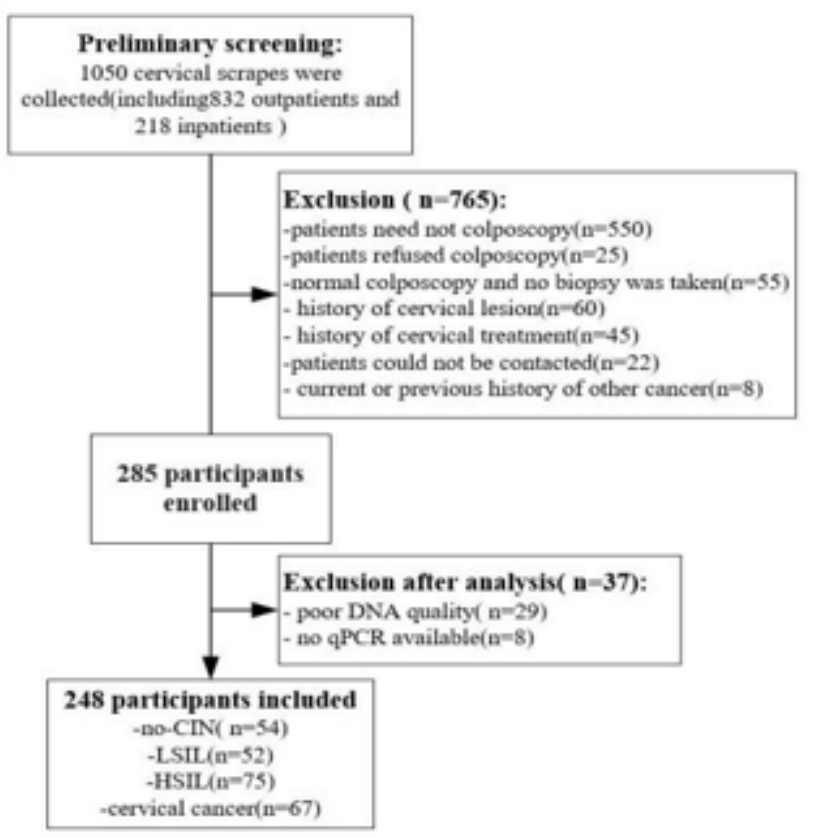

(B)

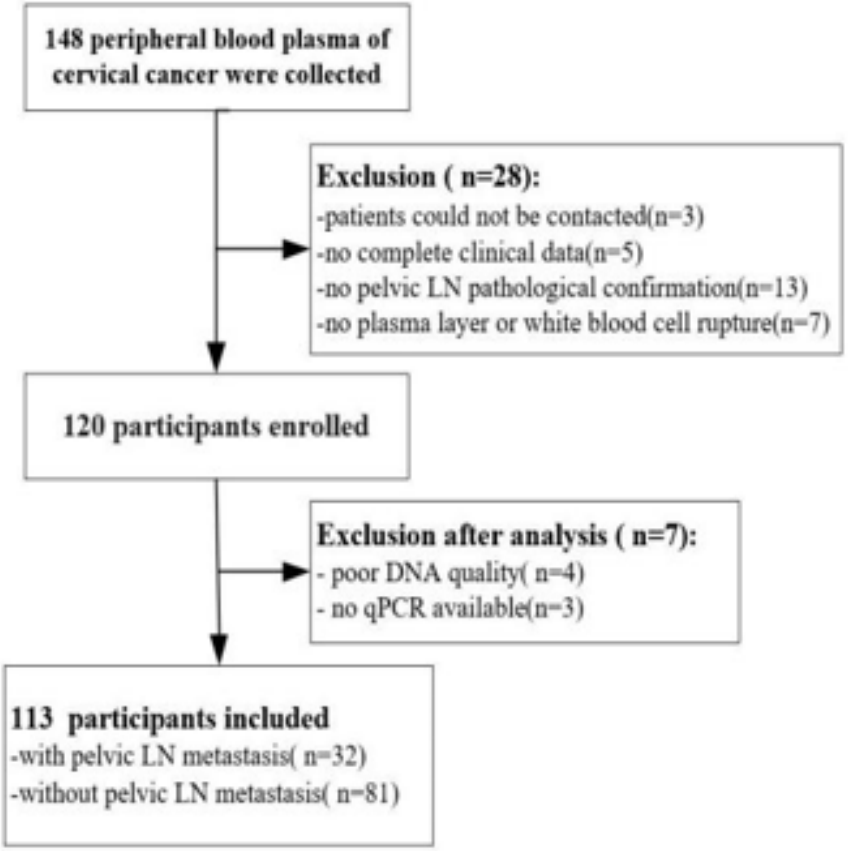

Figure 1

Flowchart of study population (A) Cervical scrapes; (B) Peripheral blood of cervical cancer. LN=lymph node 

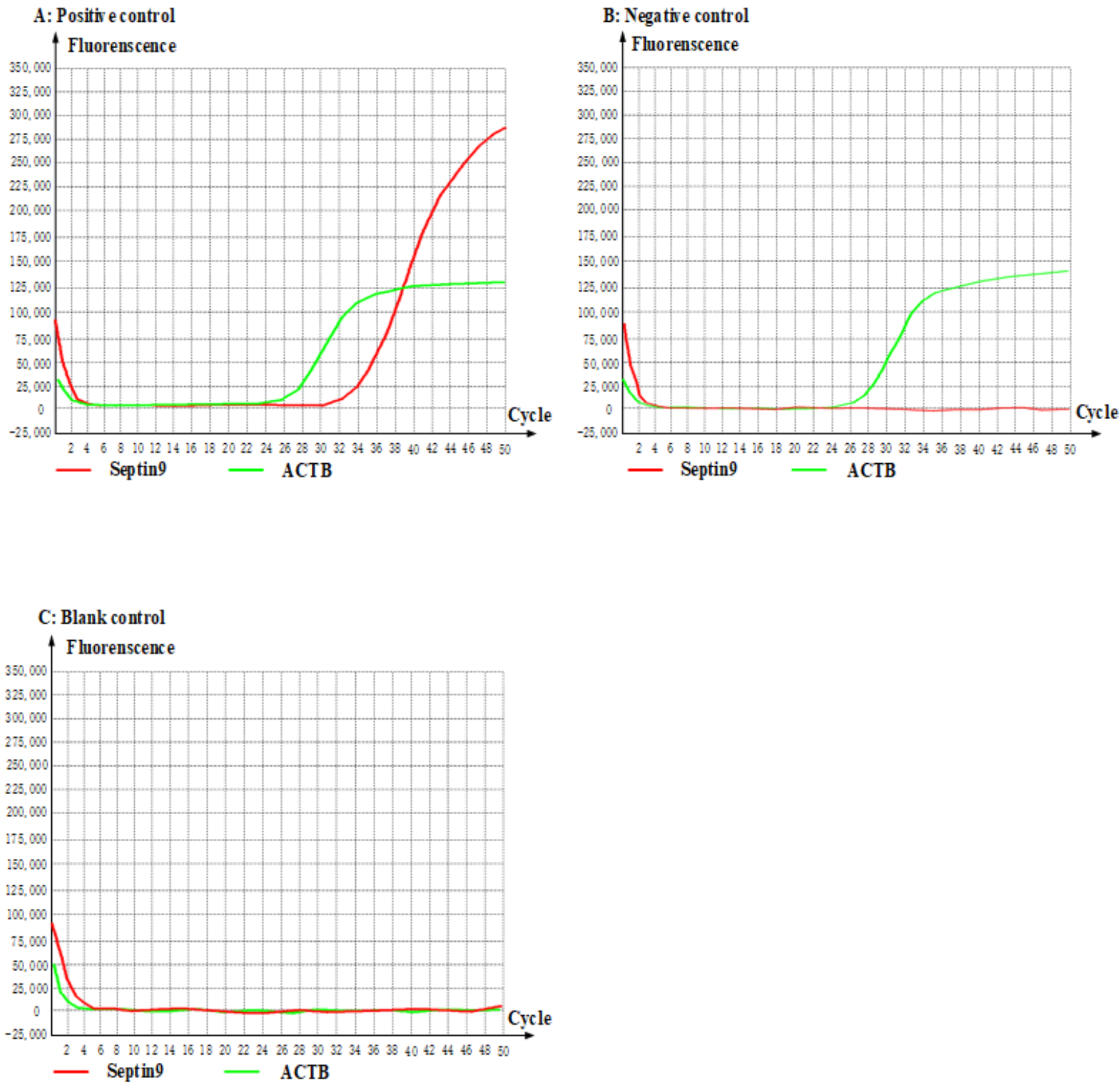

Figure 2

Amplification curve of Septin9 and ACTB genes in cervical cancer(positive control), normal peripheral blood DNA(negative control), and ddH2O(blank control) 


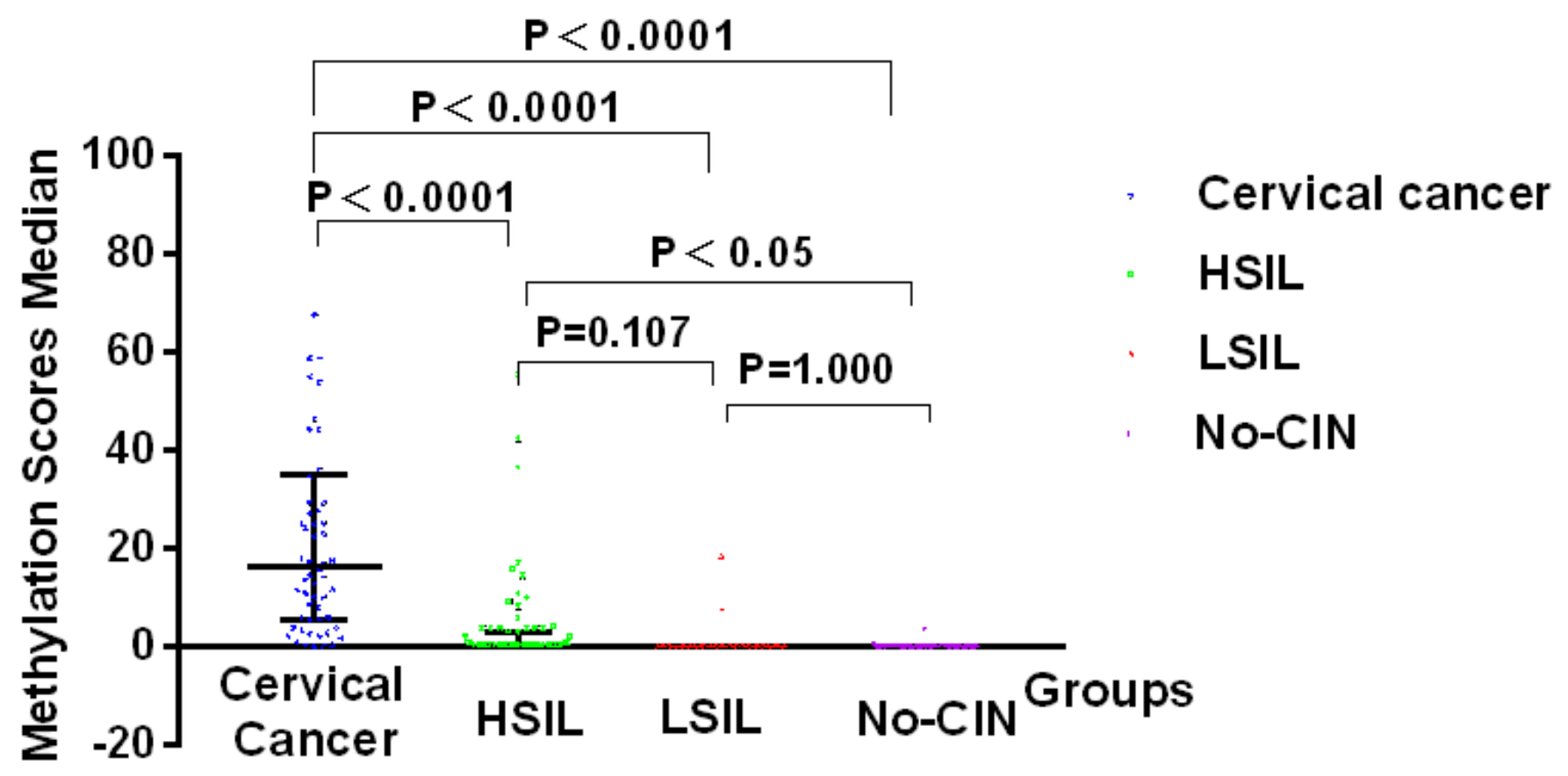

Figure 3

Methylation scores median of Septin9 with increasing severity of cervical lesions. In this box-and-whisker plot, the median lines represent median values; the upper and lower lines represent the 25th and 75th percentiles, respectively. 
(A)

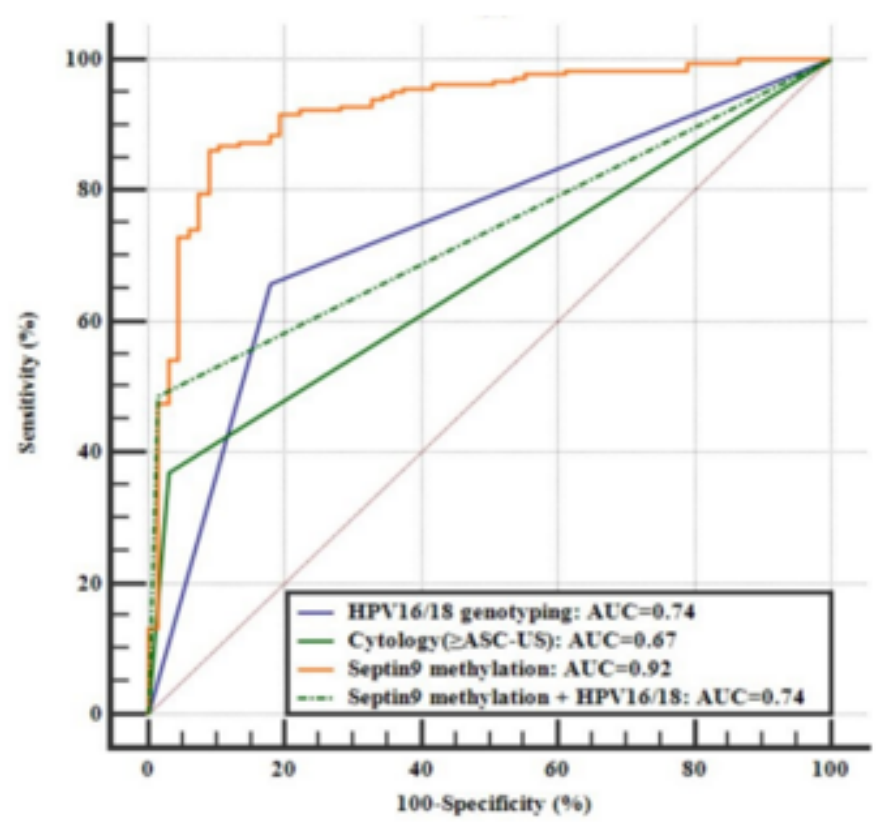

(A)

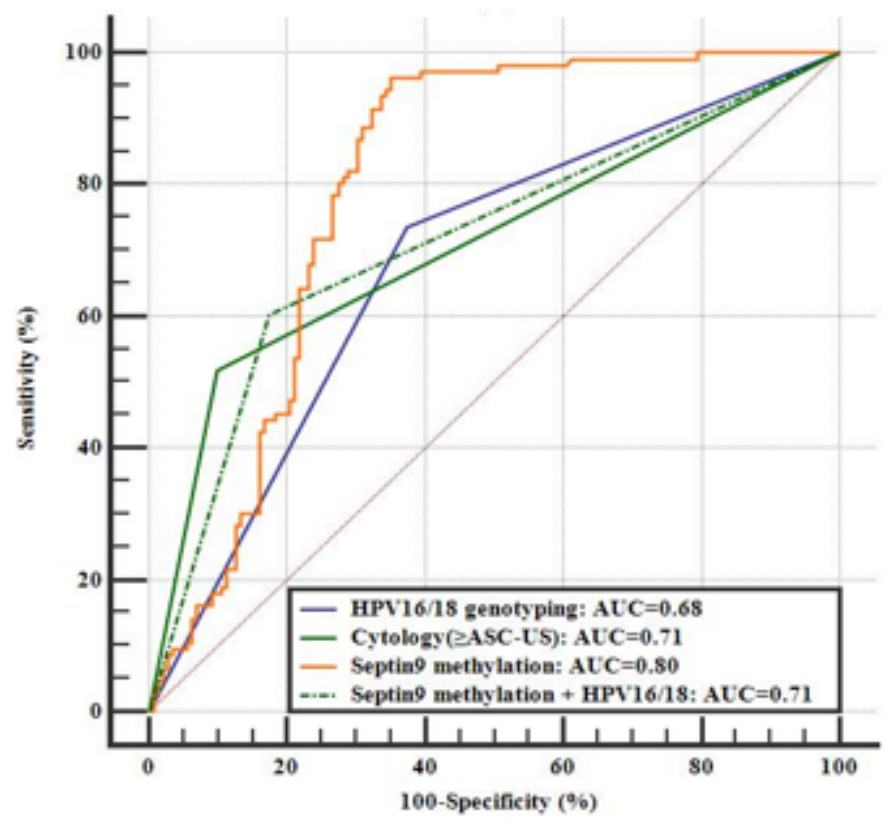

\section{Figure 4}

The diagnostic power of Septin9 methylation, cytology and HPV16/18 genotyping. (A) ROC of Septin9 methylation, cytology, HPV16/18 genotyping and Septin9 methylation $\triangle H P V 16 / 18$ in differentiating cervical cancer patients from non-cancerous patients. (B) ROC of Septin9 methylation, cytology, HPV16/18 genotyping and Septin9 methylation $\triangle H P V 16 / 18$ in differentiating $\geq$ HSIL patients from $\leq$ LSIL patients. 